\title{
Essentials in Stable Angina Pectoris
}



Juan Carlos Kaski

\section{Essentials in Stable Angina Pectoris}

Springer 


\section{Juan Carlos Kaski}

Cardiovascular \& Cell Sciences Res Inst

St George's University of London

London

UK

ISBN 978-3-319-41179-8

ISBN 978-3-319-41180-4 (eBook)

DOI 10.1007/978-3-319-41180-4

\section{Library of Congress Control Number: 2016948438}

(C) Springer International Publishing Switzerland 2016

This work is subject to copyright. All rights are reserved by the Publisher, whether the whole or part of the material is concerned, specifically the rights of translation, reprinting, reuse of illustrations, recitation, broadcasting, reproduction on microfilms or in any other physical way, and transmission or information storage and retrieval, electronic adaptation, computer software, or by similar or dissimilar methodology now known or hereafter developed.

The use of general descriptive names, registered names, trademarks, service marks, etc. in this publication does not imply, even in the absence of a specific statement, that such names are exempt from the relevant protective laws and regulations and therefore free for general use.

The publisher, the authors and the editors are safe to assume that the advice and information in this book are believed to be true and accurate at the date of publication. Neither the publisher nor the authors or the editors give a warranty, express or implied, with respect to the material contained herein or for any errors or omissions that may have been made.

Printed on acid-free paper

This Springer imprint is published by Springer Nature

The registered company is Springer International Publishing AG Switzerland 


\section{This book is dedicated to}

My wonderful wife, Marta, for her unconditional love and continued

support and inspiration; my father, who is over 90 years of age and still practices medicine with great care and devotion; and to all medical practitioners who strive to improve their knowledge to provide better care for their patients. 



\section{Preface}

Stable angina pectoris affects a large proportion of individuals in the general population. Recent data indicate that approximately seven million American people suffer from angina. This not only is a very frequent condition but one associated with an increased risk of major cardiovascular events, including myocardial infarction and cardiac death. Chronic stable angina also represents a major financial burden to many individuals affected by the condition and to health services worldwide. Angina is often, but not exclusively, caused by obstructive atherosclerotic coronary artery disease. Coronary atherosclerotic plaques causing progressive stenosis of the arterial lumen can lead to myocardial ischemia as a result of the restriction they impose to coronary blood flow. Coronary stenoses may thus limit the ability of the coronary circulation to meet an increased myocardial oxygen demand. The classical definition of angina based on the above mechanism is, unfortunately, applicable almost exclusively to myocardial ischemia caused by obstructive coronary atherosclerosis. There are, however, many other mechanisms beyond obstructive coronary artery disease that can lead to angina. Indeed, dynamic, functional mechanisms may play a key role in the genesis of angina both in the presence and in the absence of epicardial coronary artery obstructions. Abnormalities of the coronary microcirculation, which have remained elusive to conventional imaging for many years, are now accepted to play a role in "microvascular angina", a condition which is now finally capturing the attention of physicians on both sides of the Atlantic. Microvascular angina is discussed in this book in a specific chapter. The 
functional aspects of microvascular angina, its clinical presentation and prognosis, as well as the diagnostic tests used for the assessment of microvascular dysfunction are topics discussed in this book. This work also includes clinical diagnostic and therapeutic algorithms, thus trying to bring this topic closer to the practicing cardiologist. A chapter has been devoted to address the different clinical presentations of angina in women and the challenges posed by the many diagnostic and therapeutic differences determined by gender. The rational treatment of angina depends largely on the understanding of the causes and mechanisms leading to angina pectoris in the individual patient. This monographic work presents current treatments as recommended by the International guidelines but also introduces new concepts regarding unmet needs in the management of subgroups of patients with coronary artery disease as well as those affected by microvascular angina. The ultimate aim of this work is to assist the managing physician to identify the different forms of angina pectoris that may come to their attention, all of which pose important diagnostic and therapeutic challenges. In this book I argue that as the current definition (and the understanding) of angina does not necessarily encompass all of the various presentations and pathogenic mechanisms of angina, a change of paradigm is required to serve our patients better. 


\section{Acknowledgments}

I am extremely grateful to Emma Magavern, MD for her help with the formatting of the references and proofreading of the manuscript. 



\section{Contents}

1 Chronic Stable Angina Pectoris: History and Epidemiology $\ldots \ldots \ldots \ldots \ldots \ldots \ldots \ldots \ldots \ldots, 1$

Introduction $\ldots \ldots \ldots \ldots \ldots \ldots \ldots \ldots \ldots, 2$

History $\ldots \ldots \ldots \ldots \ldots \ldots \ldots \ldots \ldots, 2$

Epidemiology: Age and Gender Differences...... 7

References ........................ 10

2 Stable Angina Pectoris: Definition, Clinical Presentation and Pathophysiologic

Mechanisms ............................. 15

Characteristics of Stable Angina Pain: Typical and Atypical Angina Pectoris and Non-cardiac Chest Pain................................ 18

Pathophysiology of Angina and Different Types of Stable Angina Pectoris ................... 20

Reduced Myocardial Oxygen Supply

due to Coronary Artery Stenosis ............ 21

Fixed Coronary Obstructions Caused

by Atheromatous Plaques................ 21

How to Assess the Haemodynamic Effect of a Coronary Stenosis.................. 24

The Role of Collateral Circulation........... 24

Dynamic Coronary Obstructions in the

Epicardial Artery and the Microcirculation ..... 25

Increased Myocardial Oxygen Demand:

The Role of Increased Heart Rate as a

Trigger of Ischaemia and a Marker

of Clinical Outcome .................... 26

Combined Pathogenic Mechanisms.......... 26 
Metabolic and Functional Consequences

of Transient Myocardial Ischemia.

Coronary Microvascular Dysfunction Leading

to Microvascular Angina ... . . . . . . . . . . . . 28

Chronic Stable Angina Pectoris: Forms

of Clinical Presentation . . . . . . . . . . . . . . . . . 31

References ....................... 31

3 Angina due to Obstructive Atherosclerotic

Coronary Artery Disease: Diagnosis and

Patient Risk Stratification . . . . . . . . . . . . . . . 37

Introduction . . . . . . . . . . . . . . . . 37

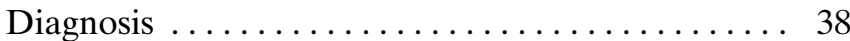

Clinical History . . . . . . . . . . . . . . . . . . . . 39

Baseline Echocardiogram and Cardiac

Magnetic Resonance Imaging (CMRI) . . . . . . . 42

Diagnostic Tests for Myocardial Ischaemia

and/or Coronary Artery Disease .......... . 44

Stress Imaging for the Detection of Myocardial

Ischaemia . . . . . . . . . . . . . . . . . . . . . . . 45

Anatomical Diagnosis of Coronary

Artery Disease ................... 50

Patient Risk Stratification as Part of the

Diagnostic Process. . . . . . . . . . . . . . . . . . 52

References .......................... 55

4 Microvascular Angina: Diagnosis, Prognosis

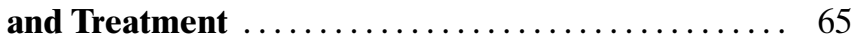

Clinical Presentation and Diagnosis . . . . . . . . . 67

Diagnostic Techniques . . . . . . . . . . . . . . . . 69

Prognosis....................... 72

Treatment of Microvascular Angina . . . . . . . . . . 77

Management of Pain Perception

Abnormalities in MVA ................ 82

Pharmacological Treatment of Pain in MVA..... 82

Non-pharmacological Treatment.............. 83

Other Supportive Measures. . . . . . . . . . . . . . . . 84

References ......................... 84 
$5 \quad$ Angina in Women $\ldots \ldots \ldots \ldots \ldots \ldots \ldots \ldots \ldots$

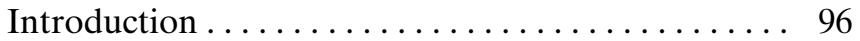

Epidemiology................... 96

Prevalence ........................ 96

Financial Burden of Angina Pectoris

in Women $\quad \ldots \ldots \ldots \ldots \ldots \ldots . \ldots . \ldots 9$

Cardiovascular Risk Factors in Women.... . . . . 98

Differences in Clinical Presentation

and Diagnosis .................... 100

Diagnostic Tests. .................... 100

Treatment and Clinical Outcomes .......... 101

References ... . . . . . . . . . . . . . . . . . . . . . . . . 104

6 Management of Angina . . . . . . . . . . . . . . 111

Introduction . . . . . . . . . . . . . . . . 111

Objectives of Treatment ............... 112

General Principles of Treatment ............. 113

Management of Typical Angina Pectoris Caused

by Obstructive Coronary Artery Disease. . . . . . . 113

Risk Factor Management and Lifestyle

Changes ... . . . . . . . . . . . . . . . . . . . . . . 113

Preventative Pharmacological Measures

with an Impact on Outcome . . . . . . . . . . . . . . 117

Symptomatic Therapies for Angina . . . . . . . . 120

Ivabradine and Clinical Outcomes.......... 133

Drugs That Improve Myocardial Ischaemia

Without Affecting Heart Rate or Cardiovascular

Haemodynamics ................... 136

Trimetazidine...................... 136

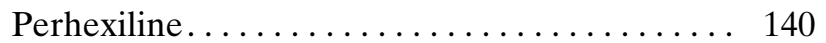

Ranolazine. . . . . . . . . . . . . . . . . . . . . . . . . 141

Other Agents. . . . . . . . . . . . . . . . . . . . . . . . 144

Revascularisation Versus Medical Therapy. . . . . 144

References ........................... 146 